Original Article

\title{
Profile of Patients Attending at the Department of Physical Medicine and Rehabilitation in a Specialized Hospital of Bangladesh
}

\author{
${ }^{*}$ Chakraborty $P K^{1}$, Islam $M J^{2}$, Hossain $M S^{3}$, Ahmed $M^{4}$, Amin $M R^{5}$, Jamal $D^{6}$.
}

\begin{abstract}
Physician's documentation has become the critical component in rehabilitation of patients. The scope of Physical Medicine and Rehabilitation (PMR) encompasses more than a single organ system. Attention to the whole person is paramount. The aim of the study was to appraise the disease pattern and demographic information of the patients received outpatient rehabilitation services at the department of PMR, National Institution of Neuroscience and Hospital, Dhaka, Bangladesh. This is a retrospective study carried out for the period of two years July 2013 to June 2015. Total number of patients was 29678, among them $57.02 \%$ were male and $42.98 \%$ were female. Maximum patients (26.15\%) were in age group $41-50$ years and in housewife (37.76\%) in occupation, where majority
\end{abstract}

1 *Prasanta Kumar Chakraborty, Assistant Professor, Department of Physical Medicine \& Rehabilitation, National Institute of Cancer Research and Hospital, Dhaka, Bangladesh ,

E-mail: pkcborty@gmail.com

2 Md. Shahadat Hossain ,Md. Jahidul Islam ,Associate Professor, Department of Physical Medicine and Rehabilitation, Dhaka Medical College, Dhaka, Bangladesh.

3 Md. Shahadat Hossain, Vice Principal and Associate Professor, Department of Physical Medicine and Rehabilitation, Shaheed Suhrawardy Medical College, Dhaka, Bangladesh.

4 Monzur Ahmed,Assistant Professor, Department of Physical Medicine and Rehabilitation, Shaheed Suhrawardy Medical College, Dhaka, Bangladesh.

5 Md. Ruhul Amin Assistant Professor, Department of Physical Medicine \& Rehabilitation, National Institute of Diseases of the chest and Hospital, Dhaka, Bangladesh.

6 Dilir Jamal, Registrar, Department of Physical Medicine \& Rehabilitation, National Institute of Traumatology and Orthopaedic Rehabilitation, Dhaka, Bangladesh.

*Corresponding Author
(56.33\%) of them came from Dhaka city. Regarding disease pattern, $56.32 \%$ was neurological, $33.46 \%$ was musculoskeletal and $7.25 \%$ of patients were suffering from rheumatologic problem. Among leading diseases, largest disease group was stroke (20.02\%), 10.48\% was non-specific low back pain, 9.92\% was Bell's palsy, 5.35\% was lumbar spondylosis, $5.13 \%$ was carpal tunnel syndrome, $4.11 \%$ was prolapsed lumber inter-vertebral disk (PLID), 3.72\% was cerebral palsy. Knowledge about the existing disease pattern and health seeking behavior is essential to provide need based health care delivery to any population.

Keywards: Profile, Diseases, National Institution of Neuroscience and Hospital, PMR.

\section{INTRODUCTION:}

Physical medicine and Rehabilitation (PMR) focuses on the restoration of function and the subsequent reintegration of the patient into the community. As with other branches of medicine, the cornerstone of PMR is a meticulous and thorough clinical evaluation of the patient. Consequently, the evaluation must assess not only the disease but also the way the disease affects and is affected by the person's family and social environment, vocational responsibilities and economic state, avocational interests, hopes, and dreams. Traditionally, the in-patient rehabilitation unit or the outpatient physiatry clinic has been the optimal setting for a comprehensive evaluation by the entire rehabilitation team. 1 Determining the degree to which a person's life is impacted by a medical condition is complex and in part perplexing. Physicians, and particularly physiatrists, are often burdened with the task of being the key interpreter. 2 The experienced physiatrist develops an intuition for how much detail is needed for each patient given a particular presentation and setting. Assessment of some or all of these elements is required for a complete understanding of the patient's state of health and the illness for which he or she is being seen. These elements also form the basis for a treatment plan.3 However, it is believed that the pattern of medical diseases in developing countries is different from that of the developed ones. 4

National Institute of Neuro-sciences (NINS) in Bangladesh was established with the vision of making this institute as the center of excellence not only in this country but also for others. It is a matter of pride that the institute has started 
functioning from September 2012. There are more than fifteen departments.5 Physical Medicine and Rehabilitation is one of them. This department tries to correlate with other departments in providing facilities, faith and satisfaction to the patients6. The total number of patients at Physical Medicine Department has been increasing day by day. Almost all the patients coming to this department were from different areas of Bangladesh by themselves or referred by physicians from different department of National Institution of Neuroscience and Hospital. In July-2013 to June- 2015 about 29678 patients were treated by PMR department of National Institution of Neuroscience and Hospital.

\section{MATERIALS AND METHODS:}

To attain disease profile and demographic information (age, sex, catchment area and occupation), we undertook a retrospective review of the records at Physical Medicine and Rehabilitation department of National Institute of Neuroscience and Hospital, Dhaka over a period of two year

Table- I. Socio-demographic characteristics of patients ( $\mathrm{n}=29678)$

\begin{tabular}{llcc}
\hline \multicolumn{2}{c}{ Characteristics } & Number of patients & Percentage (\%) \\
\hline Sex & Male & 16922 & 57.02 \\
& Female & 12756 & 42.98 \\
\hline Age (in years) & 0-10 years & 795 & 2.68 \\
& $10-20$ years & 947 & 3.19 \\
& 21-30 years & 5110 & 17.22 \\
& 31-40 years & 6853 & 23.09 \\
& 41-50 years & 7761 & 26.15 \\
& 51-60 years & 5375 & 18.11 \\
& 60-70 years & 2498 & 8.42 \\
& Above 70 years & 339 & 1.14 \\
\hline Catchment area & Dhaka city & 16718 & 56.33 \\
(Residency) & Outside Dhaka city & 12960 & 43.67 \\
\hline \multirow{6}{*}{ Occupation of of } & Service holder & 6832 & 23.02 \\
patient & Retired Service holder & 1896 & 6.39 \\
& Housewife & 11206 & 37.76 \\
& Laborer & 1290 & 4.35 \\
& Farmer & 2120 & 7.14 \\
& Businessman & 1935 & 6.52 \\
& Student & 1707 & 5.75 \\
& Unemployed & 1366 & 4.60 \\
& Others & 1326 & 4.47 \\
\hline
\end{tabular}

from first July 2013 to thirtieth June 2015 and determined the various diagnoses of attending patients. Information was extracted from the patients' hospital records by means of a questionnaire assessing the participants' demographics and diagnoses. The subjects were enrolled on an individual basis, despite the varying number of visits by a given patient during the period of study. After collection of the data in a standardized proforma, all the data were analyzed and presented in simple statistical percentage using Microsoft Excel.

\section{RESULTS:}

Table I shows the total number of 29678 patients received Physiatric management during the study period, among them $57.02 \%$ (16922) was male and $42.98 \%$ (12756) was female; $26.15 \%$ (7761) were in age range of $41-50$ years. Catchment areas were $56.33 \%$ (16718) Dhaka city and $43.67 \%$ (12960) outside Dhaka city; where 37.76\% (11206) of the studied population were housewives.

Figure-1 shows the psychiatric services provided in the department, $56.32 \%$ were neurological, $33.46 \%$ were musculoskeletal and $7.25 \%$ patients were rheumatologic condition.

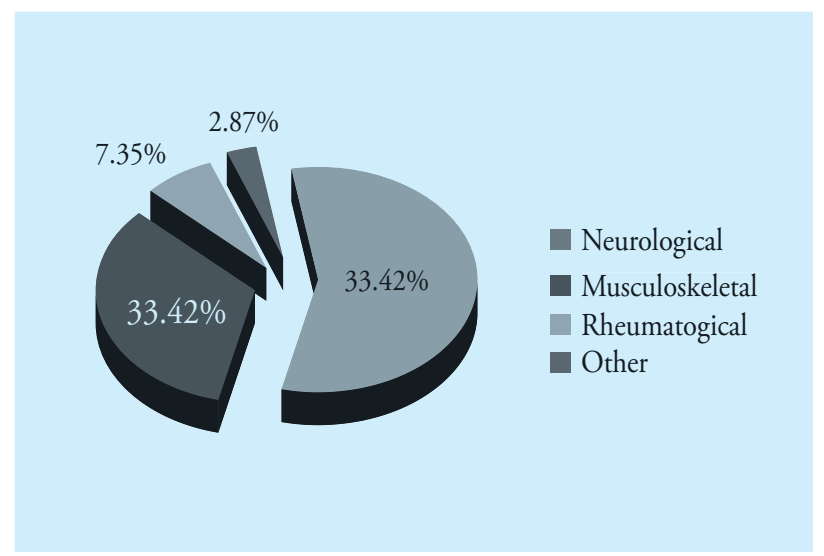

Figure-1: Physiatric services provided to the patients 
Table- II emphasizes the results related to the 29678 patients' profile of Neurological diseases. Ischemic stroke was 29.03\% encounted highest among neurological diseases. Next come Bell's palsy was $17.62 \%$.

Table-II: Neurological diseases:

\begin{tabular}{|c|l|c|c|c|}
\hline $\begin{array}{l}\text { Serial } \\
\text { Number }\end{array}$ & Disease & $\begin{array}{l}\text { Number of } \\
\text { patients }\end{array}$ & $\begin{array}{l}\text { Percentage (\%) } \\
\text { for whole } \\
\text { patients(n=29678) }\end{array}$ & $\begin{array}{l}\text { Percentage (\%) } \\
\text { for Neurological } \\
\text { diseases(n=16715) }\end{array}$ \\
\hline 1 & Ischaemic Stroke & 4852 & 16.35 & 29.03 \\
\hline 2 & Bell's palsy & 2945 & 9.92 & 17.62 \\
\hline 3 & Carpal Tunnel Syndrome & 1523 & 5.13 & 9.11 \\
\hline 4 & Cerebral Palsy & 1105 & 3.72 & 6.61 \\
\hline 5 & Hemorrhagic Stroke & 1087 & 3.66 & 6.50 \\
\hline 6 & Guillain Barre Syndrome & 764 & 2.57 & 4.57 \\
\hline 7 & Myopathy & 712 & 2.40 & 3.00 \\
\hline 8 & Motor Neuron Disease & 502 & 1.69 & 2.78 \\
\hline 9 & Parkinson's Disease & 465 & 1.57 & 2.14 \\
\hline 10 & Transverse Myelitis & 156 & 1.20 & 0.93 \\
\hline 11 & Nerve injury & 155 & 0.53 & 0.93 \\
\hline 12 & Brachial plexopathy & 28 & 0.52 & 0.17 \\
\hline 13 & Seizure disorder & 2064 & 0.09 & 12.35 \\
\hline 14 & Others & 16715 & 6.95 & $100 \%$ \\
\hline & Total & $56.32 \%$ & \\
\hline
\end{tabular}

Table- III presents the Musculoskeletal diseases as there Low back pain (non specific) was (31.32\%), Lumber spondylosis $15.98 \%$, prolapsed Lumber Inter-vertebral disc was $12.30 \%$, Cervical spondylosis and Osteo-arthritis of knee presented almost the same $10.84 \%$ and $10.57 \%$ respectively.

Table-III: Musculoskeletal diseases

\begin{tabular}{|c|l|c|c|c|}
\hline $\begin{array}{l}\text { Serial } \\
\text { Number }\end{array}$ & Disease & $\begin{array}{l}\text { Number of } \\
\text { patients }\end{array}$ & $\begin{array}{l}\text { Percentage (\%) } \\
\text { for whole } \\
\text { patients(n=29678) }\end{array}$ & $\begin{array}{l}\text { Percentage (\%) } \\
\text { for Musculoskeletal } \\
\text { diseases(n=9930) }\end{array}$ \\
\hline 1 & Low Back Pain (Non-specific) & 3110 & 10.48 & 31.32 \\
\hline 2 & Lumbar spondylosis & 1587 & 5.35 & 15.98 \\
\hline 3 & Prolapsed Lumber Intervertebral Disc (PLID) & 1221 & 4.11 & 12.30 \\
\hline 4 & Cervical Spondylosis & 1076 & 3.63 & 10.84 \\
\hline 5 & Osteo-arthritis of Knee joint & 1050 & 3.54 & 5.57 \\
\hline 6 & Neck Pain(sprain/strain) & 583 & 1.96 & 4.58 \\
\hline 7 & Lumbar radiculopathy & 455 & 1.53 & 2.07 \\
\hline 8 & Cervical Radiculopathy & 206 & 0.69 & 2.04 \\
\hline 9 & Spondylolisthesis (Lumbar) & 24 & 0.68 & 0.24 \\
\hline 10 & Osteoporosis & 435 & 0.08 & 4.38 \\
\hline 11 & Others & 9930 & 1.47 & $100 \%$ \\
\hline & Total & & $33.46 \%$ & \\
\hline
\end{tabular}

Table- IV describes the Rheumatological diseases. Adhesive Capsulitis / Periarthrosis of shoulder joint was found 36.41\%, then represented planter fascitis $15.73 \%$, polyarthritis was $14.12 \%$, spondylo-arthitis was $11.83 \%$ and tennis elbow was $10.22 \%$ and the rest percentages were minimum. 
Table-IV: Rheumatological diseases:

\begin{tabular}{|c|l|c|c|c|}
\hline $\begin{array}{l}\text { Serial } \\
\text { Number }\end{array}$ & Disease & $\begin{array}{l}\text { Number of } \\
\text { patients }\end{array}$ & $\begin{array}{l}\text { Percentage (\%) } \\
\text { for whole patients } \\
(\mathrm{n}=29678)\end{array}$ & $\begin{array}{c}\text { Percentage(\%) } \\
\text { for Rheumatological } \\
\text { diseases(n=2181) }\end{array}$ \\
\hline 1 & Adhesive Capsulitis/Periarthrosis of shoulder joint & 794 & 2.68 & 36.41 \\
\hline 2 & Plantar Fasciitis & 343 & 1.16 & 15.73 \\
\hline 3 & Polyarthritis/ Rheumatoid Arthritis & 308 & 1.04 & 14.12 \\
\hline 4 & Spondyloarthropathy/Ankylosing Spondylitis & 258 & 0.87 & 11.83 \\
\hline 5 & Tennis Elbow & 223 & 0.75 & 10.22 \\
\hline 6 & De Quervain's Tenosynovitis & 129 & 0.43 & 5.91 \\
\hline 7 & Juvenile Idiopathic Arthritis & 17 & 0.06 & 0.78 \\
\hline 8 & Others & 109 & 0.37 & 5.00 \\
\hline & Total & 2181 & $7.35 \%$ & $100 \%$ \\
\hline
\end{tabular}

\section{DISCUSSION:}

A uniform data system (UDS) for Medical Rehabilitation is maintained in USA and published annually. No such system exists in Bangladesh.6 In this study it has been tried to find out the age, sex, occupation, residency and disease pattern of the patients attending the dept. of Physical Medicine \& Rehabilitation, National Institution of Neuro-science and Hospital.

In this study, $57.02 \%$ of patients were male and $42.98 \%$ were female. Alamoudi OS et al4 in their study showed that male was $54 \%$. Nafiza A et al7 showed $63.4 \%$ patients were males and $36.6 \%$ were females with a male to female ratio of 1.7:1. Chowdhury $\mathrm{RN}$ et al8 presented their study with the male patients $(63.3 \%)$ predominated with a sex ratio was almost 2:1.

Occupations of patients were housewives (37.76\%), labourer $(4.35 \%)$, serviceman $(23.02 \%)$, farmer $(7.14 \%)$, businessman (6.52\%), students (5.75\%). Nafiza A et al7 showed $32.25 \%$ House wife, 30.40\% Businessman, 26.6\% Farmer, $10.75 \%$ Student.

This study showed $5.87 \%$ of patients were less than 20 years of age, $17.22 \%$ were $21-30$ years, $23.09 \%$ were $31-40$ years, $26.15 \%$ were $41-50$ years, $18.11 \%$ were $51-60$ years and $9.56 \%$ were above 60 years of age. Chowdhury RN et al8 showed $8.1 \%$ of patients were under 20 years of age, $16.7 \%$ were $21-30$ years, $15.5 \%$ were $31-40$ years, $26 \%$ were $41-50$ years, $18.5 \%$ were $51-60$ years and $15.2 \%$ were above 60 years of age.

In our study, among whole patients (29678), 56.32\% were neurological diseases. Among the neurological diseases(16715), majority of patients had stroke 35.53\% [Ischaemic stroke (29.03\%) and Hemorrhagic stroke(6.5\%)], Bell's palsy(17.62), carpal tunnel syndrome(9.11\%), Cerebral palsy(6.61\%), GBS(4.57\%), Myopathy(4.26\%), MND(3\%), PD(2.78\%), TM(2.14\%). Patten of neurologic diseases conducted by Chowdhury RN et al8 showed stroke was the most common (47.7\%),
PN(3.9\%), MND(3.3\%), GBS(0.9\%) etc. Mohammad QD9 in his study stated that the incidence of stroke is increasing in this country in comparison to developed country.

In this study, Among whole patients (29678), 33.46\% were musculoskeletal diseases. Among the musculoskeletal diseases (9930), majority of patients had non-specific LBP $(31.32 \%)$ and others were lumbar Spondylosis (15.98\%), PLID (12.30\%), cervical Spondylosis (10.84\%), OA knee (10.57\%). Neck pain (sprain/strain) (5.87\%), lumbar radiculopathy(Lumbago-sciatica) (4.58\%), cervical radiculopathy (2.07\%), Spondylolisthesis (Lumber) (2.04\%), osteoporosis(0.24\%). Ahmed B et al10 showed that main causes of back pain were muscle strain (39.65\%), nonspecific LBP (22.41\%), prolapsed lumbar intervertebral disc (17.24\%), lumbar Spondylosis (13.79\%) and sciatica (6.91\%). In a study done by Shahadat M11, 68.1\% patients were diagnosed as nonspecific LBP, $19.8 \%$ were lumbar spondylosis, $4.4 \%$ patients were unilateral sacralisation, $4.4 \%$ were PLID and $2.2 \%$ were spondylolisthesis. Hasan SA et al12 documented non-specific low back pain (59.95\%) as most common disease in his study.

In our study, Among whole patients (29678), 7.25\% were Rheumatological diseases. Among the Rheumatological diseases, most of the patients were suffering from Adhesive Capsulitis/Periarthrosis of shoulder joint(36.41\%) and others were Plantar Fasciitis(15.73\%), Polyarthritis/ Rheumatoid Arthritis(14.12\%), Spondyloarthropathy / Ankylosing Spondylitis(11.83\%), Tennis Elbow(10.22\%), De Quervain's Tenosynovitis(5.91\%), Juvenile Idiopathic Arthritis(0.78\%). In a rheumatological study done by Hasan SA et al12 showed that among the soft tissue rheumatism Adhesive Capsulitis(25.33\%), Plantar Fasciitis(3.65\%), Tennis elbow $(2.77 \%)$, Tendinitis/ enosynovitis(3.46\%), Juvenile Idiopathic Arthritis(0.78\%). Hasan SA et al12 also showed that among inflammatory arthritis Rheumatoid Arthritis were $36.06 \%$, Spondyloarthropathy/Ankylosing Spondylitis were $28.89 \%$ and Juvenile Idiopathic 
Arthritis(0.78\%)/Juvenile AS were 9.80\%.

Most of the patients were coming from Dhaka city (56.33\%) and from outside Dhaka city it was $43.67 \%$. Probably this situation may be due to frequent use of bus for movement and journey. Masud $\mathrm{MH}$ et al13 showed that urban patients were $75.36 \%$ and rural patients were $24.63 \%$. On the other hand, for the metropolitan area patients feel easy to reach in the hospital. Shakoor MA et al14 showed in their study that most of the patients $(65.7 \%)$ used bus for movement and journey.

From the above discussion, it is clearly demonstrated that the findings of the study performed in Physical Medicine department of National Institution of Neuro-science and Hospital is consistent with the findings of different institutes of Bangladesh.

\section{CONCLUSION:}

A majority of patients who receive Physiatric management in NINSH are middle aged and have stroke, low back pain (non specific) and Bell's palsy. This study throws some light on the pattern of diseases treated in the PMR department. There should be a large scale multi-centered study need to perform in our country and a uniform data system should be constructed for Medical rehabilitation in Bangladesh.

\section{LIMITATION:}

This study was done in a small population and secondary data (Record review) were taken.

\section{ACKNOWLEDGEMENT:}

Dr. Md. Khurshid Mahmood, Associate Professor and Head, Department of PMR; Professor M Badrul Alam, Joint Director and Professor Quazi Deen Mohammmad, Director of National Institution of Neuro-science and Hospital, Dhaka. Fellow colleagues, medical technologist and our family members.

\section{DISCLOSURE:}

Self financing, Conflict of interest is none declared and Ethical approval was not required.

\section{REFERENCE:}

1. Ganter BK, Erickson RP, Butters MA, Takata JH, Noll SF. Principle of evaluation and management. In: Delisa JA, editor, Physical Medicine and Rehabilitation-principle and practice. 5th ed. Philadelphia: Lippincott Williams \& Wilkins; 2005. p. 3-5.

2. Weiss L, Isaacson AC. General principles. In: Weiss LD, Weiss JM, Pobre T, editors, Oxford American handbook of Physical Medicine and Rehabilitation, 1st ed, New York: Oxford University Press; 2010. p.13.

3. O’Dell MW, Lin CD, Panagos A. The Physiatric history and physical examination. In: Braddom RL, editor, Physical Medicine and Rehabilitation, 4TH ed, Philadelphia: Elsevier; 2011, p.3.
4. Alamoudi OS, Attar SM, Ghabrah TM, Al-Qassimi MA. Pattern of Common Diseases in Hospitalized Patients at an University Hospital in Saudi Arabia: A Study of 5594 Patients. JKAU: Med. Sci. 2009; 16(4):3-12.

5. Mohammad QD. Establishment of National Institute of Neuroscience and Hospital, Bangladesh perspective [editorial]. J Natl Inst Neurosci Bangladesh. 2015; 1(1):1.

6. Hossain MS, Chakraborty PK, Rahman S, Islam MJ, Amin MR, Saha RK, Khan MH, Yasmin N. Diseases pattern in the department of Physical Medicine \& Rehabilitation in a tertiary level hospital. Bangladesh Med J. 2014 Sep; 43(3):130-133.

7. Nafiza A, Islam MZ, Farjana S. Pattern of Skin Diseases: Experience from a Rural Community of Bangladesh. Bangladesh Med J. 2012; 41(1):50-52.

8. Chowdhury RN, Hasibul Hasan ATM, Rahman YU, Khan SI, Hussain AR and Ahsan S. Pattern of neurological disease seen among patients admitted in tertiary care hospital. BMC Research Notes 2014, 7:202

9. Mohammad QD. Management of stroke - Bangladesh perspective. Bangladesh Med J. 2013 Jan; 42(1):34-37.

10. Ahmed B, Alam S, Rashid I, Rahman N, Rahman A, Uddin T, Azad GN. Effects of Transcutaneous Electrical Nerve Stimulation (TENS) on patients with Acute Low Back Pain. JAFMC. 2011 December; 7(2):29-32.

11. Shahadat M. A Comparative Study of the Effects of UST and SWD on the patients with chronic low back pain [Dissertation]. Dhaka: BCPS; 2005.

12. Hasan SA, Rahim MA, Bakar Siddiq MA, Hossain MS, Taslim A, Paul S, et al. Study of spectrum of rheumatic diseases in the department of Physical Medicine \& Rehabilitation, Chittagong Medical College Hospital, Bangladesh. JCMCTA. 2009; 20(1): 6-11.

13. Masud MH, Rahman MZ, Parveen S, Rana MA, Chowdhury MS, Rahman MA, et al. Demographic and Clinical Profile of Patients with Irritable Bowel Syndrome Attending in Gastroenterology Out Patient Department of BSMMU. Comilla BMA Med J. 2012 July; 27(2):15-18.

14. Shakoor MA, Islam MA, Ullah MA, Ahmed MM, Hasan SA. Clinical profile of the patients with chronic low back pain-A study of 102 cases. JCMCTA. 2007; 18(2): 16-20. 